\title{
Erratum to: Neural network nonlinear modeling for hydrogen production using anaerobic fermentation
}

\author{
Walid Mohammed Al-alayah • Abdul Amir H. Kadhum • \\ Jamaliah Md. Jahim • Ahmed El-Shafie • \\ Mohd Sahaid Kalil
}

Published online: 24 March 2013

(C) Springer-Verlag London 2013

\section{Erratum to: Neural Comput \& Applic}

\section{DOI 10.1007/s00521-012-1268-8}

Unfortunately, in the original publication, the names of four co-authors have been inadvertently missed. The complete author group is given below:

Walid Mohammed Al-alayah · Abdul Amir H. Kadhum • Jamaliah Md. Jahim $\cdot$ Ahmed El-Shafie $\cdot$ Mohd Sahaid Kalil

The online version of the original article can be found under doi:10.1007/s00521-012-1268-8.

W. M. Al-alayah

Chemical and Materials Engineering Department,

College of Engineering, King Abdulaziz University (KAU),

P.O. Box 80204, Jeddah 21589, Saudi Arabia

\begin{abstract}
A. A. H. Kadhum · J. Md. Jahim · M. S. Kalil
Department of Chemical and Process Engineering,

Faculty of Engineering and Built Environment,

University Kebangsaan Malaysia, Malaysia, Malaysia
\end{abstract}
A. El-Shafie ( $\square)$
Department of Civil and Structural Engineering,
Faculty of Engineering and Built Environment,
University Kebangsaan Malaysia, Malaysia, Malaysia
e-mail: elshafie@vlsi.eng.ukm.my 